\title{
Patrimônio e enobrecimento no Bairro do Recife
}

Rogerio Proença Leite*

\section{Resumo}

Este artigo analisa o processo de enobrecimento e as práticas de preservação do patrimônio cultural no Bairro do Recife, Pernambuco. O argumento central do artigo é que os usos e contra-usos dos espaços enobrecidos criam fissuras e demarcações socioespaciais na paisagem urbana e as tornam centros de disputas práticas e simbólicas pelo reconhecimento político e pela visibilidade pública das diferenças.

Palavras-chave: Patrimônio cultural. Enobrecimento. Espaço público. Recife antigo.

\section{Heritage and gentrification in Recife Quarter}

\begin{abstract}
This article analyses the process of gentrification and the practices of preservation of cultural heritage in the old Bairro do Recife (Recife Quarter), in Pernambuco, Brazil. The central argument of the article is that the uses and the counter-uses of the gentrification spaces create fissures and socio-spatial demarcations in urban landscape and as they make these spaces centers of practical and symbolic disputes for political acknowledgment and for the public visibility of differences.
\end{abstract}

Key words: Cultural heritage. Gentrification. Public space. Old Recife Quarter.

O ponto de partida da reflexão aqui proposta situa-se numa posição aparentemente cômoda, pois não se trata nem de um relato de experiência ou um relatório de desempenho de quem atuou em um determinado projeto de intervenção urbana, mas tão somente de uma investigação sobre as práticas de "revitalização" em curso no 
Brasil. Contudo, esse tipo de abordagem analítica pode ser, em alguns casos, um exercício muito mais incômodo do que aparenta, devido à necessária inflexão crítica que ele carrega. Dito isso, gostaria de ressaltar ainda que minhas reflexões sobre a "revitalização" do Bairro do Recife, tema sobre o qual discorrerei aqui, resultam da pesquisa por mim realizada e que deu origem a uma tese de doutorado recentemente publicada (1), e elas não têm como foco os possíveis êxitos ou fracassos do Plano de Revitalização do Bairro do Recife. O foco analítico recai sobre os impactos sociais que as intervenções tiveram na formação do espaço público naquela localidade. Para isso, gostaria de recuperar três momentos históricos de intervenções no Bairro do Recife.

\section{A fundação da MauritsStadt}

O núcleo urbano primitivo do Recife era um pequeno povoado que foi, inicialmente, apenas um istmo de Olinda com mais 10 hectares, no qual os arrecifes naturais formavam um seguro ancoradouro para as embarcações que transportavam pau-brasil e açúcar para a Península Ibérica. O "Povoado dos Arrecifes" cresceu como um porto de comércio, cujo nome vem da sua própria formação natural. A Rua do Bom Jesus, principal espaço da atual política de "revitalização", foi uma das mais significativas do Núcleo Original da cidade, segundo a opinião do historiador Evaldo Cabral de Mello (1997). Ali existiu, e daí a referência ao antigo nome - Rua dos Judeus -, uma comunidade judaica que, fugindo das perseguições na Europa, instalou a primeira sinagoga das Américas (Kahal Kadosh Zur Israel), provavelmente entre 1640 e 1641 (DANTAS, 1999).

No século XVII, o núcleo urbano era guarnecido pelas muralhas erguidas pelos holandeses, cujas portas e trincheiras garantiam a segurança da pequena vila e do porto. Ainda segundo o historiador pernambucano Vanildo Bezerra Cavalcanti (1977), existiu na Rua do Bom Jesus, até meados do século XVIII, uma dessas portas que guarneciam a pequena vila, a chamada "Porta da Terra" ou da cidadela (lantpoort), que depois foi substituída pelo Arco do Bom Jesus. Permaneceu o povoado circunscrito à estreita e insalubre faixa de terra até a vinda dos holandeses que mudaram 
substancialmente a paisagem urbana e ambiental dos Arrecifes, com a implantação do primeiro plano urbanístico do Recife.

Alterando o padrão português de ocupação litorânea, os holandeses expandiram o povoamento em direção ao continente e construíram a ponte Maurício de Nassau, a primeira a ligar o antigo istmo ao continente, consolidando outro povoado, a ilha de Antonio Vaz, que viria a ser a "Nova Maurícia" (atual Bairro de Santo Antônio). A construção dessa ponte foi um primeiro passo, não apenas para a evolução urbana em direção ao continente, como também para a primeira refuncionalização do antigo bairro portuário. Além da ponte e da transferência da sede do governo holandês para o novo povoado, a mudança da residência do Conde Nassau significou um reforço para a "Nova Maurícia", que teve a sua construção iniciada logo após a invasão de 1630 (CAVALCANTI, 1977, p.149).

Insalubre, profana e bela foi talvez a imagem mais contundente do que restou da "Mauricéia" pernambucana, antes do "bota abaixo" que arrasou o antigo bairro holandês. Hoje, nem mesmo o traçado urbano do antigo povoado lembra aquele de ruas estreitas e apertadas, onde apinhavam-se os sobrados-cortiços e os sobradosbordéis dos quais fala Gilberto Freyre em seu "Sobrados e Mucambos". Duas longas e largas avenidas rasgaram o Bairro, do mar ao rio, lembrando apenas que foi naquela direção, rumo ao continente, que os holandeses expandiram seu povoamento para fundar a Cidade Maurícia. No lugar dos sobrados-magros, foram erguidos prédios monumentais no discutido estilo eclético, modelo à época da arquitetura liberal francesa do final do século XIX. O Bairro, que cresceu sobre os escombros de Olinda incendiada, foi também palco de uma outra grande reforma que o transformou em outro documento de cultura, agora da Belle-époque francesa. Quase 300 anos depois, o Recife mais uma vez confirmaria Walter Benjamin, tornando-se ele próprio um documento da sua barbárie, ao se remodelar numa reforma que ficou conhecida como "bota abaixo" que arrasou o que havia no Antigo Recife de vestígios arquitetônicos de uma época, registros documentais da vida e arquitetura colonial holandesa. 


\section{A construção da Paris pernambucana}

A reforma do bairro portuário do Recife, a partir de 1910, seguiu a mesma tendência que se proliferou em todo país, associando modernização da estrutura portuária com renovação urbana. O período da reforma é particularmente relevante para a história econômica de Pernambuco. O Recife era, à época, a mais importante capital nordestina, centro das "novas elites urbanas" da região. Foi nesse período, como demonstra Perruci (1978), entre o final do século XIX e início do século XX, que a economia açucareira de Pernambuco passou por transformações importantes em decorrência da substituição dos antigos engenhos pela usina. Esse fato contribuiu para consolidar o capital industrial (predominantemente urbano, portanto) em detrimento do então capital agrário (e rural, conseqüentemente) em Pernambuco.

A reforma, portanto, não apenas melhorava as condições operacionais do comércio exportador/importador, como também delineava uma nova imagem para a cidade, reflexo das novas elites da economia financeira e urbana em Pernambuco, conforme ressalta Cátia Lubambo (1991). Seguindo o princípio da reforma de Haussmann das grandes avenidas, associado às idéias sanitaristas da época, o processo de intervenção urbana foi traduzido em higienização ampla das cidades, literal e metaforicamente. As reformas do Rio de Janeiro e do Recife tinham de fato a intenção de erradicar as moléstias e focos de epidemias que proliferavam nas regiões portuárias. Os focos de febre amarela e varíola, no porto do Rio de Janeiro, eram empecilhos reais à política de desenvolvimento, voltada aos investidores internacionais: havia, como ressalta Fabris (2000), receio até de desembarcar no porto da Capital Federal. No Recife, o estado de insalubridade era semelhante, senão mais grave. Em estudo de 1908 sobre o Porto do Recife, Artur Orlando enumerava os recorrentes focos epidêmicos de tuberculose, varíola, gripe, beribéri, febre tifóide, sarampo, desinteria, lepra, escarlatina e paludismo (ORLANDO, 1908, p.127).

A reforma do Porto do Recife significou, nesse sentido, tanto uma adequação urbana ao emergente capital industrial e financeiro do setor usineiro pernambucano, quanto uma intervenção voltada à higienização urbana. A Reforma de 1910 começou com as obras 
de modernização do Porto, mas a intervenção no traçado urbano do antigo bairro portuário, entretanto, não se limitou a uma recomposição de fachadas ou construções isoladas de edificações em estilo eclético: quase todo o bairro foi demolido, com o que ainda restava de exemplares da arquitetura colonial. O discurso da higienização no Recife encontra seu principal alvo nos sobrados do velho bairro portuário, cuja necessária profilaxia tinha como justificativa o caráter predominantemente insalubre de seu interior, acentuado pelo hábito de manter-se inimigo da rua.

A abertura de grandes avenidas facilitava a rápida circulação de pessoas, num cenário típico da Belle-époque: mais do que uma paisagem arquitetônica, uma cena política de construção de uma paisagem da modernidade; mais do que um trabalho de engenharia sanitária, uma operação de segregação social que limitava o livre fluxo de pessoas. $O$ ecletismo, esse estilo híbrido e mal visto pelos modernistas, caracterizado pela utilização livre e superposta de estilos do passado, representava - na arquitetura - um novo estilo de vida da burguesia emergente, estilo marcado pela monumentalidade das construções. Esta paisagem de um Brasil moderno, no entanto, também era a imagem de um Brasil real, envergonhado de si mesmo, como destaca Carvalho (1999) ao comentar as reformas no Rio de Janeiro: "No Rio reformado circulava o mundo belleépoque fascinado com a Europa, envergonhado do Brasil, em particular do Brasil pobre e do Brasil negro" (CARVALHO, 1999, p.41). O discurso da cidade reproduzia, assim, no plano urbanístico, os mesmos "estigmas eugênicos" que permeavam o debate sobre o caráter nacional no pensamento social brasileiro (LIRA, 1999).

Após a reforma, a reapropriação do Bairro se deu principalmente através de companhias de seguros, instituições bancárias e organizações ligadas ao comércio importador e exportador. Esta "elitização" teve um desdobramento político para a imagem do Bairro e seus usos. Em razão da tendência de concentração de atividades comerciais, as funções habitacionais sempre foram vistas como residuais e ao Bairro foi associada a idéia de um quartier de negócios, imagem que permaneceu associada ao bairro até os anos 50 , quando outras regiões centrais passaram a ter maior importância comercial. Entre os anos 50 e 80, o bairro mergulhou num lento e gradual processo de 
deterioração, típica das áreas centrais das grandes metrópoles, sendo revertida essa situação a partir da implantação do Plano de Revitalização, terceiro movimento de resignificação política e visual do Bairro do Recife.

\section{0 processo de enobrecimento do Bairro}

O "Plano de Revitalização do Bairro do Recife" foi uma peça bem estruturada de "planejamento estratégico" que continha uma detalhada proposta de ações a curto e médio prazo, com dimensionamento físico e estimativa de custos das obras, apresentado como proposta para o Programa Integrado de Desenvolvimento do Turismo no Nordeste - Prodetur.

O plano promoveu a caracterização de três diferentes setores de intervenção e definiu também áreas de interesse e uma espacialização das atividades, a partir das possibilidades concretas de intervenção. O Setor de Consolidação, definido como uma área estável quanto aos usos, compreendia a parte da llha onde se fixaram as atividades portuárias e as atividades institucionais. O Setor de Renovação se apresentava como uma área que oferecia "disponibilidade de transformação". Esse Setor, que ficou praticamente fora da poligonal de tombamento do IPHAN, possui as Indústrias Pilar e Moinho Recife, atividades cujas áreas de ocupação dificilmente poderiam sofrer grandes alterações, excetuando parte dos logradouros públicos que a Indústria Pilar absorveu. É nesse Setor também que está situada a Comunidade Nossa Senhora do Pilar (ou Favela do Rato), erguida numa área desapropriada pela Portobrás, em 1975. O Setor de Revitalização, que compreendia praticamente a área que depois constituiu a poligonal de tombamento, tinha seu uso do solo definido pelas atividades de "serviços modernos, o comércio varejista e a habitação". Era nesse Setor que se concentrariam os maiores projetos estruturadores do Plano, objetivando disseminar os serviços culturais, de lazer e diversão, bem como os serviços turísticos.

Os principais objetivos da proposta de "revitalização" se destinavam às atividades relacionadas aos serviços do Setor de Revitalização, transformando-o numa espécie de âncora de todo o Plano de Revitalização. O tipo de uso dos imóveis, circunscrito ao 
Setor, também facilitava sua delimitação como área privilegiada para a implantação dos serviços mais dinâmicos, relacionados ao lazer e diversão. É neste Setor de Revitalização onde há a maior concentração, por $\mathrm{m}^{2}$ de área construída, de atividades de "serviços", "habitação" e "comércio varejista", enquanto os outros Setores concentravam edificações de grande porte, como o comércio atacadista, serviços públicos e indústria.

O detalhamento técnico do Plano tinha uma justificativa clara. Como já pude assinalar em trabalho anterior (LEITE, 2004), não se tratava apenas de uma proposta de restauração do patrimônio edificado, mas de uma articulada idéia de intervenção urbana na forma de um longo empreendimento. Afinado com os pressupostos do market lead city planning (VAINER, 2000), o Plano tinha três objetivos principais, tendo como base operacional o conjunto dos Setores de Intervenção: 1. transformar o Bairro do Recife em um "centro metropolitano regional", tornando-o um pólo de serviços modernos, cultura e lazer; 2. tornar o Bairro um "espaço de lazer e diversão", objetivando criar um "espaço que promova a concentração de pessoas nas áreas públicas criando um espetáculo urbano"; 3. tornar o Bairro um "centro de atração turística nacional e internacional". Esses objetivos sinalizavam o quanto a proposta estava voltada ao incremento da economia local, pretendendo tornar o Bairro do Recife um complexo mix de consumo e entretenimento.

A noção de um espaço de "espetáculo urbano", que iria caracterizar todo o Plano, é um indicador importante de uma política de enobrecimento, na medida em que confirma o foco predominantemente econômico das ações previstas, bem como o tipo de uso esperado para cada uma delas. Para viabilizar a implementação da proposta, foram estabelecidos alguns "elementos estruturadores", dentre os quais se destacam: "Economia local com função central plena", "Espaço público para reunião e o espetáculo", "Manutenção e valorização do patrimônio ambiental e cultural", "Recuperação da imagem do Bairro". Esses "elementos estruturadores" abrangiam aspectos centrais e convergentes com as políticas de enobrecimento do urbanismo empresarial: a construção de uma nova imagem da cidade, através da valorização dos 
usos econômicos do patrimônio cultural e da espetacularização do espaço urbano, como forma de reativar os fluxos de investimentos para a economia local (FORTUNA, 1997; ARANTES, 2000). Esta imagem, construída através de uma visão que entende a cultura na perspectiva dos resultados econômicos, e a cidade como empresa, previa a concentração de escritórios de grandes empresas e corporações, reforçando, no Bairro, a "imagem de espaço central e nobre da cidade".

Os quarteirões de animação da Rua do Bom Jesus foram viabilizados não apenas pelas reformas na estrutura física da área, mas principalmente pela agenda de eventos que a Prefeitura mantém durante todo o ano, que delimita diferenciadas formas dos usos dos lugares. O cultural turn do urbanismo empresarial, sobre o qual se refere Otília Arantes (2000), passou a atuar no Bairro do Recife como mecanismo de legitimação de uma imagem atrativa para o público consumidor, bem como para novos investidores potenciais. O casario reformado transformou o lugar em um agitado ponto de encontro, por onde circulam pessoas, sob o requinte das luzes e do burburinho de muitas vozes, marchinhas de frevo ou jazz. Estrategicamente direcionados para realçar as fachadas restauradas, esses focos de luz reforçavam a impressão cenográfica das ruas, cujo impacto passou a ser um enorme contraste com todo o resto do Bairro. A partir das 18 horas, o trânsito era interditado nestas ruas e os cavaletes de madeira surgiam, acompanhando um esquema de segurança (pública e privada), que ajudava a transformar este trecho da cidade em um artificial boulevard. Pouco a pouco as ruas eram tomadas por pessoas e as calçadas pelas mesas dos bares e restaurantes. Estimava-se que, em dias de grandes eventos, pelo menos 15 mil pessoas circulavam pelas ruas, em busca de lazer e diversão. Com o apoio dos empresários do Bairro, a Prefeitura passou a manter uma intensa programação cultural: shows com artistas locais, apresentações de dança, exposições de arte na rua, festivais de seresta. Durante todo o ano, diversas atividades asseguravam a continuidade do Pólo de animação cultural, integrando o Bairro à agenda cultural da cidade. No carnaval, uma variada e intensa programação mantinha o local como uma das mais novas opções para o turista que freqüentava Pernambuco. O desfile de agremiações no Bairro era um espetáculo à parte: blocos, troças, reisados, maracatus, caboclinhos. Além dos 
inúmeros eventos itinerantes, a Prefeitura mantinha em sua programação oficial as festividades de São João, dois grandes eventos tipicamente de rua.

O impacto dos investimentos resultou em uma alteração da paisagem urbana do Bairro do Recife, cuja principal característica, voltada à criação de um mix de consumo e lazer, redesenhou o perfil do lugar: o Bairro passou a ser a área de maior concentração relativa de bares e restaurantes na Cidade do Recife. Parte da nova imagem construída para o local se baseava justamente nessa singularidade de ser um dos únicos locais em que o consumidor tem diversas opções em uma área de pequenas dimensões físicas, a exemplo de uma praça de alimentação de um Shopping Center.

Em 1998, estando em curso o amplo "Plano de Revitalização do Bairro do Recife", dáse o tombamento pelo IPHAN, que o reconhece patrimônio nacional, tendo como principal justificativa o que resultou das transformações urbanas e alterações de estilos, especialmente da grande reforma de 1910, que faria o Bairro do Recife "[...] configurarse hoje em exemplar único, íntegro, e híbrido da Paris de Haussmann no Brasil". Essa reforma, que marcaria a passagem do Recife Antigo para o Novo Recife, teria transformado o Bairro em um "[...] arquivo vivo e único da superposição das várias temporalidades que dominaram a história e a produção artística no Recife e no Brasil”.

\section{Considerações finais}

Hoje, embora não existam mais sequer ruínas das antigas "Portas do Recife", não apenas a Rua do Bom Jesus como as outras que foram "revitalizadas" parecem estar sendo circunscritas a um outro traçado simbólico de demarcação de uma nova área "Dentro de Portas": não mais de pedra e cal, mas portas mais sutis, "[...] menos aparentes que os da Antiguidade, mas igualmente práticos, constrangedores e segregativos" (VIRILIO, 1993, p.12), que redesenham uma paisagem fortificada e enobrecida, numa metáfora de um passado de guerras e invasões que se confunde com um presente marcado pela exclusão e violência. Nessa metáfora da história, o velho porto parece repetir a sua própria origem quando o antigo povoado era uma área circunscrita pelos muros holandeses, redemarcando os seus limites naturais entre $o$ 
mangue e o mar. Se as atuais fronteiras - materiais ou simbólicas - demarcam hoje o Bairro do Recife, evocando as portas e trincheiras holandesas do século XVII, os seus atuais prédios ecléticos e seu traçado urbano evocam, de outro modo, um modelo urbanístico que pretendia justamente evitar a formação de barricadas e trincheiras.

O Pólo Bom Jesus, principal local do processo de "revitalização", passou a destacar-se também pelo apelo visual das cores do seu casario. Mesmo durante o dia, quando invariáveis espacialidades pareciam predominar em todo o Bairro, a Rua do Bom Jesus já era o espaço mais entrecortado por fronteiras simbólicas. Por condensar de modo paradigmático os principais efeitos da política de gentrification (SMITH, 1996), a Rua abrigava uma pluralidade de usos contraditórios e conflituosos, como palco de maior visibilidade pública do local. A primeira fronteira que separava a Rua do Bom Jesus das demais ruas do Bairro foi erguida pelo tratamento diferenciado que a Prefeitura dispensava, através dos serviços urbanos de limpeza, segurança e iluminação. Em contraste visível com o resto do Bairro, a Rua tinha de fato, tratamento diferenciado, por representar a parte mais bem sucedida do empreendimento que transformou o antigo bairro em um local de consumo e lazer.

Linhas invisíveis não se estruturaram apenas entre os Pólos, mas no interior deles, através das diferentes possibilidades de uso do espaço urbano enobrecido e do patrimônio histórico transformado em mercadoria cultural, mediante processos que agregam valor econômico aos bens culturais (MENEZES, 2000). Assim, o sentido mais evidente, atribuído à Rua do Bom Jesus como lugar, sempre pareceu ser o de consumo. No entanto, dizer que aquela rua era apenas um lugar de consumo não explica a complexa articulação de sentidos que nela se desenvolvia. A Rua se tornou, em razão das reformas realizadas em seu patrimônio edificado, um dos espaços de maior visibilidade pública da cidade. Enobrecida, também passou a definir um estilo de vida: freqüentar seus bares sinalizava a adoção de códigos sociais de inserção em uma camada diferenciada da sociedade local. Para compartilhar esses códigos, era necessário traduzir essa anuência de sentidos nas marcas corporais e nas condutas comportamentais. Talvez como forma de diferenciar radicalmente esse público, e a 
nova imagem da Rua em relação ao que era aquele espaço antes da "revitalização" (uma rua onde moravam velhas prostitutas), o Bom Jesus se tornou um espaço sofisticado, no qual seu público raramente comportava-se de modo despojado. Com atitudes claramente defensivas, os usuários do Bom Jesus erguiam seus próprios cavaletes quando a paisagem era entrecortada pelos ruídos visuais - expressão mais perceptível dos contra-usos (LEITE, 2002 e 2004) que se instalavam naquele lugar.

Gostaria também de argumentar que a presença desses contra-usos não elimina a configuração de um lugar, mas, ao contrário, o reforça, na medida em que torna mais visíveis as fronteiras que constantemente precisam ser reafirmadas na delimitação prática e simbólica dos lugares sociais. A delimitação desses lugares, portanto, é relacional, assim como o são os processos formadores de identidades: existe em função de uma necessária diferenciação que torna o lugar uma singularidade espacial e socialmente reconhecível. Este aspecto contrastivo e diferencial implica a existência de representações que podem ser antagônicas: o que torna um espaço um lugar para uns, pode ser exatamente o que possibilita, para outros, a construção contrastiva de seus próprios lugares. É nesse sentido que um lugar é sempre um espaço da construção da diferença: nele se inscrevem as marcas que caracterizam as diferentes demandas de pertencimento a uma coletividade. É também através dessa diferenciação que um lugar pode vir a ser um espaço de cidadania: através dele podem ser demarcadas, social e espacialmente, as confluências ideológicas ou dissensões que se traduzirão na tentativa de uma reivindicação de diferentes valores culturais, interesses políticos, visões de mundo e necessidades materiais.

Por fim, temos no Brasil uma mudança no conceito de patrimônio histórico e cultural, e o tombamento do Bairro do Recife foi um forte sintoma desse processo. O processo de gentrification no Bairro do Recife foi igualmente emblemático de uma intervenção que toma o patrimônio como mercadoria e esvazia, de certa forma, os sentidos habitacionais e sociais do patrimônio e não leva em consideração os seus usuários mais antigos. O caso do Bairro do Recife tem muito a nos ensinar, até porque tem se transformado em um paradigma para muitos outros projetos. Tenho acompanhado isso 
com preocupação, pois quase todos os outros planos de intervenção no Brasil ou tomam o Recife como eixo paradigmático ou se referem a ele como referência. $E$ se o Recife é paradigmático para um modelo bem sucedido de enobrecimento, ele é também paradigmático de um processo de forte exclusão social. Até hoje os moradores da Favela do Rato estão à margem desse processo, e existem moradores que estão no bairro há pelo menos 50 anos. Outro aspecto importante que observei no Bairro do Recife - e isso é bom para pensar - é que os usuários pobres do bairro gostariam de estar presentes nos espaços enobrecidos. Pelo que pude observar, eles adentravam essas fronteiras como um desafio, uma contestação, ainda que desordenada. Para quem trabalha com política cotidiana, obviamente entende que uma participação política não precisa ser necessariamente organizada por sindicatos, partidos ou qualquer outra organização formal. Há muitas outras formas cotidianas de expressão política, como as inscrições corporais, tatuagens, roupas, gostos musicais e preferências por certos espaços da cidade que geram diferentes territorialidades. Todos esses aspectos são manifestações políticas através das quais seus agentes intentam dizer algo. É preciso, portanto, entender os contra-usos como expressões políticas cotidianas de subversão dos usos esperados dos espaços enobrecidos. São táticas e formas de reação dos chamados "desprovidos de poder", e revelam o quanto de exclusão sócio-espacial pode existir nestes processos contemporâneos de enobrecimento urbano.

\section{Notas}

(1) A tese de doutorado referida foi defendida pelo autor na Unicamp, realizada sob a orientação de Antonio Arantes, e publicada com o título de Contra-usos da Cidade: lugares e espaço público na experiência urbana contemporânea. Campinas, Editora Unicamp, 2004.

\section{Referências Bibliográficas}

Agência de Desenvolvimento Econômico do Estado de Pernambuco - AD/DIPER. Plano de Revitalização - Bairro do Recife. Planejamento Urbano e Economia vol.1. Recife, 1992. 
ARANTES, Otília. Estratégia Fatal. In: ARANTES, O.; VAINER, C.; MARICATO, E. A Cidade do Pensamento Único. Petrópolis: Vozes, 2000.

CARVALHO, Marcus J.M. Recife, controles e contrastes (1822-1856). In: SOLLER, M.A.; MATOS, M.I.S. (orgs). A cidade em debate. São Paulo: Olho D’água, 1999.

CAVALVANTI, Vanildo Bezerra. Recife do Corpo Santo. Recife: PMR, 1997.

DANTAS, Leonardo. Recife, História de um Bairro. In: Processo n .1168-T-85/ IPHAN, Conjunto Arquitetônico e Paisagístico do Antigo Bairro do Recife e Cais do Apolo, no Município de Recife, Estado de Pernambuco. Arquivo Noronha Santos, IPHAN, 1999.

FABRIS, Annateresa. Fragmentos Urbanos: representações culturais. São Paulo: Studio Nobel, 2000.

FORTUNA, Carlos. Destradicionalização e Imagem da Cidade: o caso de Évora. In: FORTUNA, C. (org). Cidade, Cultura e Globalização: ensaios de sociologia. Oeiras: Celta, 1997.

LEITE, Rogerio Proença. Contra-usos e Espaço Público: notas sobre a construção social dos lugares na Manguetown. Revista Brasileira de Ciências Sociais, vol.17, n.49, jun. 2002.

. Contra-usos da Cidade: lugares e espaço público na experiência urbana contemporânea. Campinas:

UNICAMP, 2004.

LIRA, José Tavares Correia de. O urbanismo e seu outro: raça, cultura e cidade no Brasil (1920-1945). Estudos Urbanos e Regionais, $\mathrm{n}^{\circ}$ 1, maio 1999.

LUBAMBO, Cátia Wanderley. O Bairro do Recife: entre o corpo santo e o marco zero. Recife: CEPE/Fundação de Cultura Cidade do Recife, 1991.

MELLO, Evaldo Cabral de. Rubro Veio: o imaginário da restauração pernambucana. Rio de Janeiro: Topbooks, 1997.

MENEZES, Ulpiano Toledo Bezerra de. Valor Cultural, Valor Econômico: encontros e desencontros. Seminário Internacional História e Energia. São Paulo: Fundação Patrimônio Histórico de Energia de São Paulo, 2000.

ORLANDO, Artur. Porto e Cidade do Recife. Pernambuco: Typographia do Jornal do Recife, 1908.

PERRUCI, Gadiel. A República das Usinas. Rio de Janeiro: Paz e Terra, 1978.

SMITH, Neil. The New Urban Frontier: gentrification and revanchist city. London: Routledge, 1996. 
VAINER, Carlos B. Pátria, empresa e mercadoria: notas sobre a estratégia discursiva do planejamento. In: ARANTES, O.; VAINER, C.; MARICATO, E. A Cidade do Pensamento Único. Petrópolis: Vozes, 2000.

VIRILIO, Paul. O Espaço Crítico. Rio de Janeiro: Editora 34, 1993.

* Cientista Social. Mestre em Sociologia. Doutor em Ciências Sociais. Professor do Departamento de Ciências Sociais da Universidade Federal de Sergipe. 